\title{
EL RACISMO ESTRUCTURAL Y LA EXPANSIÓN DE LAS FRONTERAS DEL AUTORITARISMO EN AMÉRICA LATINA
}

\section{STRUCTURAL RACISM AND THE EXPANSION OF THE FRONTIERS OF AUTHORITARIANISM IN LATIN AMERICA}

Anny Ocoró Loango ${ }^{1}$

\begin{abstract}
Resumen
El presente artículo analiza cuatro fronteras de la exclusión que hoy están en expansión en nuestra región. Estas fronteras se relacionan y se retroalimentan entre sí. Se trata de las fronteras de la desigualdad y la exclusión; las fronteras del racismo estructural; las fronteras del capital que avasalla los territorios y las culturas de los pueblos indígenas y afrodescendientes; y las fronteras del autoritarismo. Muestra cómo en el contexto actual se está expandiendo, en algunos países de la región, un discurso autoritario que, de la mano de la extrema derecha y de sectores conservadores y evangélicos, propaga discursos de odio, se sirve del racismo estructural para blindar sus privilegios y para intentar consolidar su hegemonía cultural. Con el fin de discutir estos cuatro ejes, priorizaré una perspectiva étnico-racial que partirá de una mirada a las poblaciones negras o afrodescendientes en América Latina, y que constituyen, junto a los pueblos indígenas, las poblaciones más castigadas por la desigualdad en esta región.
\end{abstract}

Palavras-chave: Racismo, autoritarismo, fronteras de la exclusión, desigualdades.

\begin{abstract}
This article analyzes four frontiers of exclusion that are currently expanding in our region. These borders are related and feed into each other. These are the frontiers of inequality and exclusion; the borders of structural racism; the borders of capital that overwhelm the territories and cultures of indigenous peoples and Afro-descendants; and the borders of authoritarianism. It shows how, in the current context, an authoritarian discourse is spreading in some countries of the region which, hand in hand with the extreme right and conservative and evangelical sectors, propagates hate speech, uses structural racism to shield its privileges and to try to consolidate its cultural hegemony. In order to discuss these four axes, I will prioritize an ethno-racial perspective that will start from a look at the black or Afro-descendant populations in Latin

\footnotetext{
1 Doctora en Ciencias Sociales y Master en Ciencias Sociales con Orientación en Educación de la Facultad Latinoamericana de Ciencias Sociales (FLACSO - Argentina). Actualmente se desempeña como docente de posgrado en FLACSO y en la Universidad Nacional de Tres de Febrero (UNTREF). Es integrante de la Cátedra UNESCO "Educación Superior y Pueblos Indígenas y Afrodescendientes en América Latina". Preside la Asociación de Investigadores/as Afrolatinoamericanos/as y del Caribe AINALC. Ha publicado varios artículos en revistas académicas latinoamericanas sobre afrodescendientes y políticas educativas con perspectiva étnico -racial y de género. Líneas de Investigación: Afrodescendientes y educación; Políticas educativas con perspectiva étnico - racial y de género; Racismo y educación; Feminismos negros; Género, racismo y educación; Currículo y diversidad cultural.
} 
America, and who constitute, together with the indigenous peoples, the populations most affected by inequality in this región

Keywords: Racism, authoritarianism, borders of exclusion, inequalities.

"Todavía buelo la espuma del mar que me bicieron atravesar.

La noche, no puedo recordarla. Ni el mismo océano podría recordarla. Pero no olvido el primer alcatraz que divisé. Altas, las nubes, como inocentes testigos presenciales. Acaso no he olvidado ni mi costa perdida, ni mi lengua ancestral Me dejaron aquí y aqui he vivido. Y aqui volvi a nacer". Nancy Morejón

\section{INTRODUCCIÓN}

Hoy estamos ante un cambio de dimensiones profundas que no ocurren sólo por la crisis sanitaria y económica que desató el COVID19. Evidentemente una nueva sociedad está naciendo. La expansión digital es una realidad de la que posiblemente ya no nos podemos sustraer, y las plataformas virtuales están transformando totalmente nuestra vida cotidiana y la organización social y económica de las sociedades actuales. Se están produciendo cambios en el mundo del trabajo, y nuevos modos de organización de las instituciones y de la vida cotidiana. Muchas de las narrativas que daban coherencia, sentido y cohesión a las sociedades se encuentran en declive. Para muchos autores/as de la teoría social, este futuro es visto muchas veces, desde la perspectiva de un mundo globalizado en riesgo, un mundo a la deriva y a merced de intereses espúreos. La imagen del futuro aparece monopolizada por la automatización y la digitalización de la vida, y resulta difícil no imaginar ese futuro sin escuchar estas visiones que anticipan nuevas y mayores crisis globales de las que emergen la incertidumbre y desesperanza.

A pesar de ello, me permitiré apelar al optimismo, y con ello pienso que las amenazas de la humanidad van a ser contenidas. Me permitiré dar lugar a la utopía para pensar que tendremos un mundo con oportunidades para todos/as, en el que todos los pueblos, culturas, formas de vida, epistemologías y saberes serán valorados. En realidad, para lograr que un futuro más humanizado y democrático sea posible, necesitamos prestar atención a las fronteras que están emergiendo en nuestras sociedades y que amenazan la calidad de nuestras democracias. Hoy podemos encontrar, en la región, cuatro fronteras de exclusión que ocupan un lugar central, y que a la vez se relacionan 
y retroalimentan entre sí. En efecto, el discurso autoritario del racismo se está expandiendo. De la mano de la extrema derecha, se sirve como instrumento de sectores conservadores y religiosos evangélicos con el objeto de blindar sus privilegios y construir una hegemonía cultural, a través de la propagación de discursos de hostilidad y odio. Las cuatro fronteras a las que me refiero son:

I. Las fronteras de la desigualdad y la exclusión

II. Las fronteras del racismo estructural

III. Las fronteras del capital que avasalla los territorios y las culturas de los pueblos indígenas y afrodescendientes

IV. Las fronteras del autoritarismo en expansión

Para discutir estas cuatro problemáticas, priorizaré una perspectiva étnico-racial que partirá de una mirada a las poblaciones negras o afrodescendientes en la región, las cuales junto a los pueblos indígenas constituyen las poblaciones más castigadas por la desigualdad en esta región.

\section{FRONTERAS DE LA DESIGUALDAD Y LA EXCLUSIÓN}

Según el Banco Mundial (BM, 2018), una de cada cuatro personas latinoamericanas se identifica como afrodescendiente. Esto representa un total de aproximadamente 133 millones de personas. De acuerdo con este organismo, en la década anterior, los afrodescendientes experimentaron algunas mejoras en su situación, producto de las políticas de inclusión social y de factores favorables en la economía regional. Esto se vio materializado en el acceso a servicios, reducción de la pobreza y reconocimiento cultural. En consecuencia, “entre 2002 y 2012, más de 80 millones de personas salieron de la pobreza, muchas de ellas pertenecientes a minorías históricamente excluidas" (BM, 2018, p.10).

En esta primera década también hubo, en América Latina, una reducción de las tasas de pobreza extrema, aunque desafortunadamente esta no se dio en forma equitativa (CIDH, 2017). En lo que respecta a los/as afrodescendientes, este organismo también señala que, aún cuando en los últimos veinte años aumentaron los niveles de ingreso y se ha logrado un crecimiento económico regional, “(...) persisten enormes brechas entre los afrodescendientes y el resto de la población” (CIDH 2017, p.130).

Como bien lo ha marcado la Comisión Económica para América Latina CEPAL (2016), en esta región, existe una matriz de desigualdad social que es necesario atender como objetivo 
prioritario. Este organismo hace referencia a desigualdades históricas, estructurales y multidimensionales; se trata de desigualdades de índole territorial, étnico-racial, socio-económica, de género y de agencia.

La CEPAL, en reiteradas oportunidades, ha destacado las desventajas históricas y estructurales que viven las poblaciones indígenas y afrodescendientes, especialmente en el acceso a la educación y al mercado de trabajo. También se manifiestan en el precario acceso a la salud, la seguridad social, la vivienda y los servicios públicos en general. Las asimetrías generadas por cuenta de la desigualdad estructural, asociadas a factores étnico-raciales, también se expresan en el hecho de que estas poblaciones, en general, desarrollan los trabajos menos calificados y, en su mayoría, en condiciones de precarización dentro del mercado informal de trabajo, lo cual reproduce las desventajas acumulativas y restringe sus posibilidades de movilidad social. Como bien afirma la OIT "el arrinconamiento sistemático de ciertos grupos en los extremos más bajos del mercado de trabajo fomenta la desventaja de estos últimos en materia económica y su inferioridad dentro de las categorías sociales, así como la transmisión de la pobreza de generación en generación” (2003, p. 25).

Al mismo tiempo, como han señalado numerosos organismos internacionales, estas poblaciones viven por debajo de la línea de pobreza, lo cual es un agravante ya que "la mayoría de las víctimas de los efectos acumulativos de la discriminación múltiple se encuentran entre los segmentos más pobres de la población” (OIT, 2003, p. 137). Desafortunadamente, los pueblos indígenas y afrodescendientes presentan niveles de pobreza muy superiores a otros grupos. La proporción de afrodescendientes en condiciones de pobreza crónica es más del doble que para los no afrodescendientes, y se incrementa para el caso de los hogares encabezados por mujeres (BM, 2018). Con referencia a la educación, el Banco Mundial (2018) señala que los niveles de escolaridad en la educación primaria son aproximadamente de un 64\% para afrodescendientes frente a un $83 \%$ para los no afrodescendientes, y sólo el 30\% de estos logra completar la educación secundaria. Con respecto al nivel terciario, sólo un 5\% logra completarlo, lo que representa un porcentaje inferior al promedio general que es del 14\%. En las áreas rurales, estos indicadores presentan aún mayores diferencias.

\section{MUJERES AFRODESCENDIENTES, BRECHAS Y DESIGUALDADES}

Tanto en América Latina como en el Caribe, los niveles de pobreza de las mujeres son más elevados que los de los hombres (PNUD, 2016). La brecha salarial entre mujeres negras y hombres blancos es muy profunda. Según la ONU-CEPAL (2017), la situación de las mujeres 
afrodescendientes muestra coincidencia, en términos generales, en todos los países de la región. Claramente la pobreza es un indicador frecuente de la desigualdad que padecen. En el caso de las mujeres afrodescendientes, estas desventajas se profundizan y conforman una brecha estructural que afecta su bienestar y su autonomía (CEPAL, 2016).

Las mujeres afrodescendientes son las más afectadas a la hora de conseguir trabajo (ONUCEPAL, 2017). En el mercado laboral, como parte de la herencia colonial, ellas sufren la reproducción de patrones históricos de discriminación. En su mayoría, se hallan vinculadas a tareas de cuidado o al trabajo doméstico, muchas veces en condiciones laborales que no cumplen con los requerimientos de trabajo decente, en los términos en los que lo define la OIT ${ }^{2}$. En Brasil y Uruguay, por ejemplo, el trabajo doméstico remunerado es uno de los sectores donde hay mayor participación de mujeres afrodescendientes (PNUD, 2017). De hecho, “en cinco de los países que cuentan con datos (Argentina, Brasil, Ecuador, Panamá y Uruguay), las mujeres afrodescendientes representan el grupo poblacional más afectado por el desempleo en el mercado laboral y en tres de estos (Argentina, Brasil y Uruguay), su tasa de desempleo es el doble o incluso más del doble que la de los hombres no afrodescendientes" (ONU-CEPAL, 2017, p. 30). Existe un alto porcentaje de mujeres indígenas y afrodescendientes en trabajos domésticos que aún enfrentan precarización y discriminación en el campo laboral. Particularmente para el MERCOSUR, distintas mediciones muestran que "más del 90\% de quienes se desempeñan como trabajadores del hogar son mujeres," lo cual significa el 6,7\% de la población urbana económicamente activa (PNUD, 2017, p.2). La desigualdad social se manifiesta, además, en el acceso a la seguridad social o en la afiliación al sistema de pensiones. Dada su mayor vinculación al mercado laboral informal o en condiciones laborales precarias, el acceso a la seguridad social en la vejez es francamente limitado.

Las mujeres afrodescendientes también se ven afectadas por la discriminación racial y el racismo. La matriz de la desigualdad que ellas padecen está atravesada, además del género y la clase, por la diferencia étnico/racial. Unida a la desigualdad y la exclusión que enfrentan, la invisibilidad estadística en la que se encuentran vulnera sus derechos y afecta la creación de políticas públicas específicas para atender sus problemáticas (CEPAL, 2016). Es evidente que estas poblaciones son víctimas de racismo y discriminación, una situación que afecta su acceso a una vida digna y al ejercicio pleno de sus derechos fundamentales.

\footnotetext{
2 La noción de "trabajo decente" fue dada a conocer por vez primera en el año 1999, en la Memoria del Director General a la 87.a reunión de la Conferencia Internacional del Trabajo. De acuerdo con la OIT, el trabajo decente debe cumplir cuatro objetivos estratégicos: "la promoción de los derechos fundamentales en el trabajo; el empleo; la protección social y el diálogo social". Pues "no se trata simplemente de crear puestos de trabajo, sino que ban de ser de una calidad aceptable” (OIT, 1999, parágrafo 1), ver: http://www.oit.org/public/spanish/standards/relm/ilc/ilc87/rep-i.htm
} 
Históricamente, las mujeres indígenas y afrodescendientes han sufrido diversas formas de discriminación y racismo que aún hoy perduran en la sociedad. El sexismo, el racismo y los prejuicios de clase complejizan su vida, reflejando las múltiples discriminaciones que enfrentan, así como las barreras de género y étnico-raciales que limitan sus oportunidades y sus condiciones de vida. Según la CEPAL (2016):

Las desigualdades de género, étnicas y raciales constituyen ejes estructurantes de la matriz de la desigualdad social en América Latina y configuran brechas estructurales de bienestar, reconocimiento, autonomía y ejercicio de los derechos de las mujeres con relación a los hombres y de los pueblos indígenas y afrodescendientes con relación a las poblaciones no indígenas ni afrodescendientes. Más aún, esas desigualdades (...) se entrecruzan y se potencian, lo que se evidencia principalmente en las profundas brechas que marcan la condición de las mujeres indígenas y afrodescendientes (p. 23).

\section{DEMANDAS DE LOS AFRODESCENDIENTES POR EL RECONOCIMIENTO Y LA IGUALDAD RACIAL}

A fines del siglo XX y comienzos del XXI, se intensificaron en toda América Latina las demandas de movimientos indígenas y afrodescendientes por el reconocimiento cultural y el acceso a derechos económicos, sociales y culturales (Ocoró, 2015). En la década de los noventa, Brasil (1988), Colombia (1991), Ecuador (1998) y Venezuela (1999) produjeron reformas constitucionales que dieron reconocimiento a los pueblos indígenas y afrodescendientes. La Constitución paraguaya de 1992 reconoció la preexistencia de los pueblos indígenas, y en diversos artículos se reconoce el derecho de estos pueblos al desarrollo de su identidad étnica, sus sistemas de organización social, y la propiedad comunal de la tierra, entre otros. Este reconocimiento también fue adoptado por la Constitución Argentina de 1994, la cual garantizó el respeto a la identidad étnica y cultural de estos grupos. En Brasil, la Constitución de 1988 ya había reconocido a las poblaciones indígenas y sus derechos sobre las tierras tradicionalmente ocupadas.

En las dos últimas décadas del siglo pasado, en el marco de las reformas multiculturales, algunos países de la región dieron pasos importantes hacia el reconocimiento de las poblaciones afrodescendientes como parte de su historia, su cultura y su realidad presente, rompiendo con la larga invisibilización que ha acompañado la vida de estas poblaciones en América Latina. Conforme fuimos entrando en el actual siglo, y con el impulso global que significó la Conferencia Mundial contra el Racismo, la Discriminación Racial, la Xenofobia y las Formas Conexas de Intolerancia (Durban, 2001), gran parte de los estados latinoamericanos emprendieron acciones que derivaron 
en políticas y programas orientados a mejorar las condiciones de vida de las poblaciones afrodescendientes.

Mas allá de sus alcances, las reformas constitucionales en los distintos países implicaron un nuevo rumbo en las relaciones entre el Estado y las minorías étnicas. Dichas reformas han contribuido a replantear la concepción de ciudadanía clásica y el reconocimiento de la pluriculturalidad en el interior de los Estados, y han pasado a ser un indicador de la democratización de la región (OCORÓ, 2015). Es así que tanto los pueblos indígenas como los afrodescendientes lograron visibilizarse como actores políticos importantes en la discusión por la igualdad, la democratización y la lucha contra el racismo.

Podemos comprender, entonces, que, durante las últimas décadas, una creciente preocupación por la situación de los afrodescendientes y de los pueblos indígenas ha dado lugar a la aparición de distintas políticas y normativas en su beneficio. No obstante, para estas poblaciones aún existen fuertes dificultades para el acceso pleno a derechos, así como también altos índices de desigualdad $^{3}$ y discriminación, secuela del colonialismo y la esclavización, lo cual no debilita, sino que fortalece las fronteras de la desigualdad y la exclusión.

\section{LAS FRONTERAS DEL RACISMO EN AMÉRICA LATINA}

Entendemos el racismo como un fenómeno histórico y complejo que no sólo afecta a las personas afrodescendientes e indígenas. Debemos decir que el racismo está enraizado en las sociedades latinoamericanas; "su existencia se funda en una creencia básica: los seres humanos se dividen en razas; entre las razas existen jerarquías que determinan la superioridad o inferioridad según sea el caso- de unas frente a las otras" (VELAZCO CRUZ, 2016, p. 381). Si bien el racismo tiene anclaje en las prácticas individuales, es decir, es ejercido por individuos, tiene también una fuerte existencia estructural (OCORÓ, 2014).

El racismo implica una práctica construida a partir de la jerarquización e inferiorización racial o étnica. Desde ya que la división de los seres humanos en razas es arbitraria y obsoleta, pero a pesar de los cambios sociales que se han producido en nuestras sociedades, este fenómeno sigue continúa vigente en la vida cotidiana. Para ver este asunto en profundidad, es importante tener en cuenta que las sociedades latinoamericanas se desarrollaron a partir de ideologías racistas que, a

\footnotetext{
${ }^{3}$ Para el año 2010 el PNUD manifestó que, en América Latina, la desigualdad está caracterizada por tres rasgos: "es alta, es persistente y se reproduce en un contexto de baja movilidad socioeconómica" (PNUD, 2010:19).
} 
través de la glorificación de la identidad nacional blanco-mestiza y del mito de la democracia racial, buscaron negar las raíces negras e indígenas y sus aportes a la historia y la cultura de los Estados nacionales (OCORÓ, 2015). Durante mucho tiempo, el discurso racista y de negación de la alteridad ha estado presente en nuestras sociedades; es más, en la búsqueda de modelos homogéneos de ciudadanía, los Estados implementaron distintas políticas de invisibilización y asimilación que pretendían borrar las prácticas culturales y la identidad de estas poblaciones. En efecto, uno de los mayores retos que han enfrentado estos grupos ha sido romper con las narrativas e imaginarios nacionales que les asigna un lugar subalterno dentro de la historia de la nación y los invisibiliza en el presente, limitando, así, su acceso pleno a derechos ciudadanos (OCORÓ, 2016).

Tanto el racismo como la discriminación constituyen factores generadores de pobreza en la región, y producen profundas desventajas, en especial para las poblaciones indígenas y afrodescendientes. Estas desventajas son acumulativas y limitan el ejercicio de los derechos de estas poblaciones. En América Latina la desigualdad racial y la desigualdad de clase "van entrelazadas y no es posible separarlas" (WADE, 2011, p.24). De ahí que existe una relación directa entre pobreza, exclusión y color de la piel, la que se remonta al período colonial. Además, tanto el racismo como la discriminación constituyen factores generadores de pobreza. Estas desventajas son acumulativas y persisten sin alteración perceptible, limitando o bloqueando la movilidad social de este grupo poblacional.

El racismo es un fenómeno estructural que tiene muchas formas de manifestarse, y que viene acompañando nuestras sociedades desde tiempos remotos. Como bien señala Almeida, "el racismo no es un acto o un conjunto de actos y tampoco se resume a un fenómeno restringido a las prácticas institucionales; es, sobre todo, un proceso bistórico y político en que las condiciones de subalternidad o de privilegio de sujetos racializados es estructuralmente reproducida" (ALMEIDA, 2018, p. 29).

En América Latina, y como producto de la trata esclavista desplegada en el marco de las relaciones coloniales, el color de piel negra está inferiorizado. Las poblaciones negras quedaron asociadas y presas dentro de una estructura que las degradó, cosificó y animalizó. En consecuencia, existe un modo de pensarlas y de ver su historia y su identidad desde un lugar subalterno que limita su acceso pleno a los derechos ciudadanos. Esta situación, en realidad, no puede soslayarse a la hora de pensar las especificidades que el racismo adquiere en nuestras sociedades. Recordemos que el discurso racista, presente en nuestras sociedades, se ha manifestado principalmente contra los pueblos indígenas y afrodescendientes. Lamentablemente, por décadas, las sociedades latinoamericanas buscaron negar las raíces negras e indígenas, así como también sus aportes a la historia y la cultura de los Estados nacionales. 
La manera cómo el racismo opera para algunos cuerpos es diferente; por eso es importante asumir una perspectiva interseccional que permita identificar cómo el racismo se articula con otras desigualdades vulnerando aún más la calidad de vida y los derechos de quienes lo padecen. Más allá de su clara dimensión estructural, el racismo también se manifiesta en situaciones cotidianas, como, por ejemplo, cuando el color de la piel se emplea para marcar a alguien como inferior o, en algunos casos, como sucede en la Argentina, cuando se utiliza para desnacionalizar o extranjerizar a la persona. También existen otras formas de racismo oculto, silenciosas, que muchas veces pasan inadvertidas. En el caso de los afrodescendientes, el fenotipo es usado como marcador social, lo cual limita su ascenso social.

El racismo adquiere características específicas en cada contexto, y es por este motivo que requiere ser pensado como un fenómeno socio-histórico que se reactualiza en todo momento. En realidad no existe un racismo trans-histórico que funciona de la misma manera en todos los contextos. El racismo instala jerarquías entre las personas que operan a modo de frontera, la frontera entre lo humano y lo no humano, en un primer momento, la frontera en quienes tienen la inteligencia y la calidad moral y quienes no gozan de ella, y la frontera entre aquel al que se le presume superior y a quien, por el contrario, se le interioriza. En algunos casos, como ocurre en la Argentina, los rasgos fenotípicos trazan una frontera de la nacionalidad; a quién considero parte de esta nación y a quién extranjerizo por que sus rasgos fenotípicos no se corresponden con los que el relato oficial eurocéntrico instaló. Dichas jerarquías son reproducidas y naturalizadas a través de los medios, la familia, la escuela y las instituciones políticas, entre otras. Este fenómeno se manifiesta cotidianamente y atraviesa nuestras instituciones; es por ello que también se habla de racismo institucional. En realidad, existe toda una estructura organizativa y cultural que apoya, produce y reproduce la jerarquización del valor de las personas.

Efectivamente, vivimos en una sociedad que jerarquiza las diferencias, algunas de las cuales son vistas como marca de inferioridad y son empleadas para legitimar desigualdades, al punto que se crean prejuicios y discriminaciones que terminan naturalizándose. En las sociedades actuales, desafortunadamente, la diversidad se ha convertido en una excusa, en muchos casos, para discriminar y negar el acceso a derechos y oportunidades a las poblaciones tanto indígenas como negras.

\section{LAS FRONTERAS DEL CAPITAL QUE AVASALLA LOS TERRITORIOS Y LAS CULTURAS DE LOS PUEBLOS INDÍGENAS Y AFRODESCENDIENTES}


Desde hace varias décadas, los pueblos indígenas y afrodescendientes vienen realizando fuertes movilizaciones para denunciar los proyectos de explotación de los recursos naturales que ponen en riesgo la preservación de sus territorios. Estos proyectos, impulsados desde los Estados, en el marco de la apertura económica y la globalización son, en muchos casos, contrarios a sus derechos y sus tradiciones. Es fundamental tener en cuenta que el territorio para los pueblos indígenas y para las comunidades negras y quilombolas no es sólo un recurso natural, sino que es también un espacio de reproducción de su cultura.

ARBOLEDA (2018) propone, para analizar el caso colombiano, el concepto de "Ecogenoetnocidio": un concepto de gran originalidad que le permite dar cuenta del modo en que el conflicto armado, los megaproyectos mineros y agrícolas capitalistas, la desidia del Estado y el racismo estructural condenan a las poblaciones negras al destierro y a la pérdida de sus condiciones de existencia. Desde mi perspectiva, este conceptoresulta mucho más apropiado para entender el contexto colombiano, pues avanza más allá de lo sostenido por el difundido concepto de "necropolítica" de Achile MBEMBE (2011), al considerar que en el contexto colombiano no hay sólo una política de muerte contra poblaciones negras, sino también contra los territorios, las visiones de mundo y de existencia de las poblaciones negras, sus saberes y sus prácticas de cuidado, entre otras.

El "Ecogenoetnocidio" expresa la continuidad de un pasado colonial en lo que respecta a la violencia ejercida contra las comunidades subalternizadas; y también; también hace visible cómo las epistemologías, cosmovisiones, espiritualidades y territorios de las comunidades negras en Colombia se han visto afectadas por el conflicto. Esta situación se extiende, además, a los pueblos indígenas, ya que también sus culturas están siendo avasalladas en nombre de la modernización y el progreso. En otras palabras, se trata de la pérdida del derecho a existir. La cuestión no afecta sólo a los seres humanos; sino también a otras especies y ecosistemas que son avasallados, y cuyas fronteras son derribadas por la lógica voraz del capitalismo. Cuando se irrumpe en forma violenca e los modos de vida de las comunidades tradicionales indígenas y negras, se pierden con ellas muchos ecosistemas que son resguardados por una visión más holística y ontológica del desarrollo, vale decir, se pierde una concepción de la vida territorial en conexión espiritual y ancestral con la naturaleza y con la diversidad biocultural. Las fronteras como lugares de preservación de una cultura están siendo subyugadas; el capital devora y deshace las fronteras ético-culturales y con ellas, los saberes, las prácticas y culturas que protegen el territorio, que cuidan de él, para mercantilizarlo y favorecer la acumulación de los sectores concentrados de la economía. 
Este despojo territorial y la violencia que enfrentan estos pueblos hoy, ante la embestida de la frontera del capital con sus grandes megaproyectos económicos, se articula con el racismo estructural, ya que esta virulencia no se puede comprender sin tener en cuenta que los territorios, los saberes y las identidades de los pueblos negros e indígenas han sido calificados como pueblos inferiores. Esto autoriza el despojo y la violencia, en tanto son vistos como pueblos sin valor.

\section{FRONTERAS DEL AUTORITARISMO EN EXPANSIÓN}

En los últimos años, el ascenso institucional de la derecha en algunos países de la región, producto de la avanzada conservadora y neoliberal, no sólo ha implicado el resurgir de políticas neoliberales que retiran al Estado de importantes áreas de la política social, sino que también se profundiza el racismo estructural, la xenofobia, las desigualdades sociales y las opresiones múltiples. A pesar de cumplirse casi veinte años de la Declaración de Durban 2001, la desigualdad y la injusticia racial continúan en una franca avanzada regional.

Para las/os afrodescendientes son tiempos difíciles, ya que los derechos conquistados en el marco de las recomendaciones de la Conferencia Internacional de Durban, en varios países, han retrocedido y están seriamente amenazados. Las desigualdades étnico/raciales se profundizan, aún más, cuando se vinculan con el género, la clase, la orientación sexual, entre otras, y culminan erosionando la capacidad de agencia y de movilización de las poblaciones negras.

En una entrevista realizada por la Agencia de Periodismo Investigativo, el historiador portugués Manuel Loff advierte sobre el ascenso de la extrema derecha a nive global, y menciona que el bolsonarismo puede expandirse a cualquier sociedad de América Latina. Al respecto plantea que:

El "bolsonarismo" es simplemente la suma de esa nostalgia por la dictadura, discurso sobre la corrupción -por tanto, demagogia moralista-, a lo que se añade después la conexión con el mundo evangélico. Si esas tres condiciones se dieran en otras sociedades latinoamericanas, el 'bolsonarismo' podría expandirse, conseguiría replicarse. Veo características muy semejantes en las derechas venezolana, mexicana, argentina y chilena (VIEL, 2019, p. 1).

La derecha regional, incluso aquella más liberal, calla frente a la perversidad de Bolsonaro y sus ataques al pueblo brasileño, a los líderes opositores, a los movimientos sociales, a las poblaciones negras e indígenas. El gobierno de Bolsonaro ha construido con un discurso contrario 
a los movimientos sociales y políticos opositores, los grupos indígenas, y los afrodescendientes, entre otros.

Cuando observo lo que acontece en Brasil, me pregunto: ¿qué es aquello que está naciendo en la sociedad y que está en expansión?, ¿qué está pasando con los lazos sociales y qué tipo de subjetividades están emergiendo en un contexto cargado de odio racial, de misoginia, de racismo, de antifeminismo y de fundamentalismo crisitiano como el desplegado por el bolsonoarismo? $\mathrm{Me}$ pregunto, al mismo tiempo, ¿qué es aquello que los sectores medios y populares que lo apoyan consiguen encontrar ahí?, ¿qué es lo que hace que los sectores populares sean parte de la base social que sostiene el bolsonarismo?, ¿cómo podemos, entonces, disputarle a la extrema derecha este espacio de avanzada sobre las libertades, sobre las resistencias, sobre los derechos de los/as ciudadanos/as? Aquí la frontera del autoritarismo avanza, se está corriendo de la mano de discursos neofacistas, racistas y patriarcales que legitiman cualquier expresión de violencia frente a los adversarios políticos o frente a cualquiera que exprese una visión política progresista.

Quien hoy transita por América Latina puede observar cómo reaparecieron los discursos que proclaman la libertad de mercado, la no intervención estatal, las privatizaciones, entre otros, discursos que fueron tan difundidos en los años 90 (OCORÓ, 2018). Como ejemplo, podemos mencionar el informe que recientemente publicó el Banco Mundial, para el gobierno de Temer, llamado "Un ajuste justo". En este se afirma que el gasto en educación es "ineficiente y regresivo", y recomienda la privatización de las universidades públicas de Brasil, argumentando que esto permitirá equilibrar el gasto público y beneficiar las políticas de reducción de la pobreza. Lo que este organismo claramente propone son políticas neoliberales, cuyos efectos profundizarían las desigualdades sociales.

Los movimientos ultraconservadores, fundamentalistas, evangélicos y religiosos, están en ascenso y participan por la disputa para construir interpretaciones del mundo. Si algo nos ha mostrado la historia es que no podemos subestimar el rol que estos grupos cumplen en la sociedad. La religión ocupa un lugar central en la construcción de las subjetividades que proclaman hoy una salida autoritaria. No se trata sólo de un "aparato de dominación ideológica" como planteaba ALTHUSSER (1975); se trata de un poder que construye subjetividades y prácticas ultraconservadoras que se alinean sin duda alguna al statu quo. La teoría weberiana mostró el papel central que tuvieron la religión y la racionalización para la modernidad capitalista. Es por ello que es un frente que no podemos soslayar del análisis, ni desatender de la praxis política. En consecuencia, "estamos ante un nuevo escenario donde actores conservadores, élites, derechas, pero también sectores de la sociedad civil, que acompañan estos consensos, participan de la construcción de nuevos sentidos políticos y 
culturales, tratando de imponer su propia interpretación de la sociedad y de construir hegemonía culturap"4 (OCORÓ, 2018, p.).

\section{LA REARTICULACIÓN DE LA EXTREMA DERECHA}

La extrema derecha latinoamericana viene articulándose y reedita el discurso racista para construir hegemonía en distintas capas de la sociedad. La frontera del bolsonarismo se está corriendo no sólo en Brasil, sino que esta agenda política de odio también está ganando espacio político en la Argentina. Si bien en este país existe un gobierno que está en las antípodas de Bolsonaro, el clima de intolerancia creciente y de odio de clase está tomando impulso en un sector de la sociedad. Este sector coquetea con modelos autoritarios o camina en esa dirección, impulsadao por los grandes poderes mediáticos, en los que incluyo a las redes sociales, una fracción del poder político, del poder empresario y del evangélico, los que no tienen reparo y han perdido el decoro a la hora de ejercer una presión abierta para salvaguardar sus intereses. Estos sectores, lo vemos en el caso argentino, en el marco del ASPO (aislamiento social, preventivo y obligatorio) han incentivado a la toma de las calles, y las protestas contra la cuarentena no tardaron de llenarse de consignas políticas que alimentan fronteras étnico-raciales y culturales, que pueden terminar de aglutinarse en torno a un significante vacío en la perspectiva en la que lo piensa LACLAU (2005) ${ }^{5}$.

Argentina y Brasil enfrentan hoy un nuevo escenario que exhibe un fuerte respaldo de algunas fracciones de la sociedad que desdeñan el ciclo de gobiernos anteriores, y que exhiben mucha virulencia hacia quienes son contrarios a sus ideas. Lo que aparece en sus expresiones tiene tal nivel de violencia que no sólo se busca sacar al otro del juego político, sino borrarlo de su proyecto de país, de su modelo nacional. Esta situación, sin lugar a dudas, nos pone en estado de alerta en lo que respecta a la calidad de nuestros sistemas democráticos, y debería conducirnos a pensar estrategias de largo plazo que apunten a desactivar estos discursos de odio.

Hay también una debilidad institucional en nuestros países latinoamericanos, lo que hace o permite que determinados actos de horror cometidos por la dictadura sean parte de las narrativas que intentan acabar con el adversario político. Es el "todo se vale"; la política se quedó sin decoro y el juego sucio se instaló, halló su espacio. Hay un uso manipulador y negacionista de la historia

\footnotetext{
${ }^{4}$ Podemos hacer mención a las declaraciones del Jefe de Ministros, Marcos Peña, cuando en una entrevista expresó: "En la Argentina se piensa que ser crítico es ser inteligente, pero nosotros creemos que ser entusiasta y optimista es ser inteligente, y que el pensamiento crítico llevado al extremo, le ha hecho mucho daño a la Argentina" (Diario registrado 11-9-17).

5 Ese "significante vacío", de acuerdo con LACLAU (2005), emerge de la articulación de fuerzas heterogéneas, descontentos y reclamos. Estas demandas puede llegar a canalizarce a través de la figura de un líder. Es este liderazgo el que unifica esas demandas y las aglutina en un discurso político.
} 
de la dictadura, lo cual es altamente peligroso, pues la debilidad de nuestras instituciones hace que no exista ningún tipo de sanción para este tipo de actos. Las continuas apologías a la dictadura, por parte de los miembros del partido del gobierno en Brasil, o bien la reciente conmemoración del asesinato del Che Guevara en Bolivia, llevada a cabo por el gobierno de facto, evidencian la virulencia y la exsacervación de la violencia a la que están dispuestos estos sectores. En referencia a la conmemoración, la "presidenta” de facto Jeanine Áñez expresó: "La lección que dimos los bolivianos al mundo con la derrota y la muerte del Che Guevara en Bolivia es que la dictadura comunista aqui no tiene paso. Ni la comunista, ni la fascista, ni la populista, ninguna dictadura pasará ni echará raices en esta nación (...) lo que jamás permitirá la tradición republicana del pueblo boliviano es la instalación de la tiranía" (PÁGINA 12, 09/10/20). También señaló que en los últimos años Bolivia enfrentó “un enemigo en casa”, y advirtió que cualquier extranjero "sea cubano, venezolano, argentino" que vaya a "causar problemas, encontrará la muerte" (PÁGINA 12, 09/10/20).

El pasado golpe de estado que vivió Bolivia el 10 de noviembre de 2019, cuando el presidente Evo Morales en Bolivia fue obligado a renunciar "a favor de la paz de país”, mostró el papel central del racismo en el golpe y su uso para afianzar autoritarismo e ir en contra de las mayorías. El nivel de sevicia con el cual fueron atacados los/as funcionarios/as del gobierno de Evo Morales, así como los militantes del MAS (Movimiento al Socialismo), partido político de Morales, puso en evidencia cómo el conflicto entre las zonas del altiplano, que concentra buena parte de la población indígena, y la zona baja del sector oriental del país, sigue latente y está atravesado por el racismo ${ }^{6}$.

La "presidenta" de facto Jeanine Áñez borró numerosos tweets racistas que había publicado antes del golpe. En uno de ellos, que data del 5 de octubre de 2019, Áñez nombra a Evo Morales, quién aún era presidente del país, como: "pobre indio aferrado al poder".

En el marco del golpe, Añez Chávez entró a la casa de gobierno con una biblia en la mano y expresó: "La Biblia vuelve a Palacio". Los sectores fundamentalistas cristianos tuvieron un rol central en el golpe de estado que vivió Bolivia. Cabe mencionar, también, que posteriormente la ministra de comunicaciones del gobierno de facto exhibió con morbosidad la "suite presidencial" de Evo Morales y expresó: "Parece la habitación de un jeque árabe" (PÁGINA 12, 18/1/2019). Esta expresión, sin duda, se asienta en ideologías racistas que parten de la idea de que un hombre indígena no es considerado merecedor de esos privilegios. El golpe en Bolivia se valió del racismo

\footnotetext{
${ }^{6}$ Durante los días del golpe pudimos ver la violencia con la cual los simbolos indígenas fueron atacados. Luis Fernando Camacho, uno de los principales organizadores del golpe quemó la bandera indígena (la wiphala), que el Estado boliviano había tomado como símbolo de la plurinacionalidad que reconoce treinta y seis nacionalidades distintas. Las fuerzas de policias también arrancaron la wiphala de sus uniformes.
} 
de aquellos sectores que sintieron que ningún indígena tenía el derecho de gobernarlos, y eso explica la inusitada violencia racial con la que fueron atacados los pueblos indígenas, así como sus símbolos ${ }^{7}$.

Este nuevo autoritarismo se funde con fundamentalismos religiosos y con visiones ultraconservadoras, y se nutre del racismo, tornándose en espacios profundamente reaccionarios. Esta nueva derecha fusiona el conservadurismo de sectores contrarios a las demandas del feminismo y de los grupos LGBTIQ+, y a lo que ellos han venido denominando "ideología de género", lo que ha venido ganando espacio político en el parlamento como ocurre en Brasil, o concentrando fuerza en las calles, como empieza a verse en la Argentina en las manifestaciones contra el aborto, o en la capacidad de influenciar el voto contrario al proceso de paz, como ocurrió en Colombia. Este nuevo autoritarismo también es auspiciado por empresarios y por grandes cadenas de medios que fogonean la mordacidad de estos grupos como una forma de ejercer presión sobre la voluntad de los gobiernos, y para alimentar la construcción de una sociedad donde cada quien quede librado al azar, y así, en consecuencia, el Estado siga siendo el garante de sus intereses.

En una entrevista al Diario La Nación, el sociólogo francés François Dubet sostiene que, en sociedades afectadas por una historia colonial como la nuestra, la posibilidad de construir igualdad es mucho más débil. Al respecto plantea:

Si las sociedades industriales europeas han sido relativamente igualitarias, como los Estados Unidos durante un cierto período, es porque esas sociedades se han percibido como particularmente homogéneas y solidarias a través de sus instituciones y los movimientos sociales. Por el contrario, cuando las sociedades son menos integradas, menos "desarrolladas" y más fuertemente escindidas entre los sectores modernos y los sectores tradicionales, porque su historia se mantiene marcada por la conquista colonial y las divisiones étnicas y raciales, la voluntad de igualdad social es claramente más débil y la distancia entre los diversos grupos sociales se mantiene profunda, a pesar de la fuerza de los imaginarios nacionalistas y "revolucionarios". (las negritas son nuestras). (LANACIÓN, 08/30/2015).

La historia colonial y el racismo nos ha marcado a todos/as,; estas son fuentes de las que se nutren las jerarquizaciones, el individualismo y la falta de solidaridad que existe en nuestras sociedades. Tanto en Argentina como en Brasil existe un fuerte descontento de una parte importante de la sociedad hacia los planes de asistencia social que el Estado implementa hacia los sectores más precarizados de la sociedad. Este ha sido un argumento para criticar con extrema

\footnotetext{
${ }^{7}$ El domingo 18 de octubre del presente año, Luis Arce Catacora, del MAS ganó la presidencia con un holgado truinfo que vuvelve a poder a Bolñivia en la senda de la democracia.
} 
fuerza a los gobiernos en los que el Estado ha tenido un papel más activo en la generación de políticas sociales. También hizo parte de las contiendas electorales, bajo la consigna: "íbamos a ser Venezuela", que estuvo presente en casi todas las campañas electorales de la derecha de los últimos años en la región.

Los / as beneficiarios de los planes sociales son vistos, por algunos sectores, como "vagos" que viven de la ayuda del Estado, y a expensas de los aportes del resto de la sociedad; al mismo tiempo, los gobiernos que han impulsado estas políticas son tildados de populistas y corruptos. La cuestión de fondo no es económica; por el contrario, dichos planes resultan escasos para combatir las enormes brechas que existen en la sociedad. La cuestión quizás se vincule con el hecho de que ciertos sectores sociales se sienten molestos porque otros sectores pueden aproximarse $-\mathrm{O}$ ya se hallan más próximos- a su estándar de vida. Resulta imposible no darse cuenta que la disputa está más ligada a la preservación de los privilegios y del poder. Gonzáles Fraga, ex director del Banco Nación durante el gobierno de Mauricio Macri, al hacer una crítica a la política económica del anterior gobierno (el kirchnerismo) expresó: "Le biciste creer a un empleado medio que su sueldo medio servia para comprar celulares, plasmas, autos, motos e irse al exterior. Eso era una ilusión. Eso no era normal" (Diario La Nación, 05/26/2016). Por supuesto, para este funcionario, no es normal que los sectores populares puedan acceder a algunos privilegios que las clases medias y altas han detentado toda su vida. Es por ello que como bien plantea Dubet (2015) “defendemos las pequeñas desigualdades que nos son favorables" y en algún punto "no somos sólo víctimas de desigualdades sociales, somos también un poco sus autores". (LA NACIÓN, 08/30/2015). A modo de ejemplo, mientras escribo este artículo, el diputado nacional y presidente del partido opositor la Unión Cívica Radical en Argentina, Alfredo Cornejo, expresó:

La verdadera grieta no es peronista y antiperonista. Es entre la gente que produce y trabaja y se esfuerza para generar riqueza y el sector parasitario que viven de quienes crean riqueza. El peronismo de hoy, que es el kirchnerismo, está representando más a los que no trabajan que a los que trabajan y crean riqueza. Representa al sector parasitario". (EL CRONISTA, 18/10/2020).

Estos discursos son sumamente peligrosos, pues rompen los lazos de solidaridad e instalan divisiones y polarizaciones en la sociedad. En efecto, se trata de un discurso que viene siendo muy eficaz, pues contribuye a sembrar descontento social y odio hacia las experiencias de gobiernos progresistas desarrolladas en la región en la primera década y principios de la segunda década de este siglo. Esto también conduce a que "en ocasiones, quizás sin gritarlo pero de manera perfectamente democrática, las sociedades eligen políticas -y politicos- que conducen a mayores niveles de desigualdad. En otras 
palabras, la injusticia social no es solo resultado de las tendencias ingobernables de la economía o la mala praxis de la gestión estatal; también puede ser popular" (NATANSON, 2017, p.1).

\section{A MODO DE CIERRE}

Si queremos "que nadie se quede atrás en la agenda del desarrollo", como lo plantea la agenda 2030, tenemos que trabajar para construir una nueva hegemonía a favor de la igualdad, un nuevo consenso político y social que entienda el crecimiento con igualdad, y con políticas antirracistas y solidarias que no vean a las personas que menos tienen como parásitos, sino que cuestione el sistema de relaciones desiguales de nuestras sociedades. En ese sentido cabe preguntarnos:

¿Cómo lograr poner límite a las políticas inequitativas y regresivas que "liberan" las condiciones para que los grandes capitales puedan expandir sus ganancias sin mayores contratiempos?

¿Cómo podemos poner límites, no a un gobierno, sino a las formas de percibir las relaciones con los otros que afectan la calidad de la vida democrática de nuestra región, y que nos atrasan como sociedad, al tiempo que horadan nuestra capacidad de agencia política y de movilización social?

¿Cómo podemos desplegar acciones transformadoras que desactiven, en la vida cotidiana, las prácticas racistas incentivadas por los grandes medios y narrativas de la extrema derecha?

Hoy tenemos acceso a gran cantidad de información que nos llega continuamente, podríamos decir, nos bombardea, y es necesario interpretar, contextualizar y, en muchos casos, hasta defendernos de ella. Es un mundo complejo y, en particular en América Latina, es necesario desplegar acciones contrahegemónicas que impidan la expansión de los capitales que arrasan pueblos, saberes, recursos naturales y culturas, es decir acciones que frenen la expansión de las fronteras del autoritarismo y del racismo, y que nos ayuden a formar a las futuras generaciones a través de una educación que los prepare para rechazar las salidas autoritarias crecientes en la región y, sobre todo, para quebrar las fronteras de la exclusión. La educación es, sin duda, una gran aliada; esta es la razón por la cual es imperativo contribuir con el desarrollo de escuelas justas que, más allá del mérito, habiliten el camino hacia la neutralización de las desigualdades sociales, de manera tal que los que tengan menos oportunidades puedan ascender y mejorar su calidad de vida, en el sentido más integral de este concepto. La educación y formación escolar podrán, así, ayudar a romper las estructuras políticas sobre las que se sostienen el racismo, la desigualdad y la exclusión. 
Resulta imperioso trabajar para la formación de ciudadanos pluralistas, globales, que entiendan que no existe una única cultura, sino culturas plurales, contribuyendo a construir una cultura común, donde "lo común" se convierta en algo abierto, plural, intercultural, y no en lo monocultural, patriarcal, y heteronormativo como lo ha venido siendo hasta el momento. La lucha pacífica también debe estar presente, para que la voz de los grupos menos favorecidos no sea silenciada, eliminada ni desvalorizada. Se necesita promover la defensa de los valores democráticos y la garantía de los derechos de todos los seres que habitan el planeta, para avanzar en la defensa de una sociedad más libre, justa e igualitaria, pues este mundo sólo va a ser mejor si todos los grupos, y todas las personas, pueden vivir en un plano de igualdad. La envergadura de los problemas que nos aquejan requiere de soluciones conjuntas, articuladas, tal vez complejas, para construir una sociedad que "no es la única posible", y en la cual la interculturalidad, la equidad y el antirracismo deberán convertirse en ejes transversales prioritarios.

\section{REFERÊNCIAS}

ALMEIDA, S. L. de. O que é racismo estrutural? Belo Horizonte: Letramento, 2018.

ALTHUSSER, L. Ideología y aparatos ideológicos del Estado. Nueva Visión. Buenos Aires, 1975.

ARBOLEDA, S. Ecogenoetnocidio Afrocolombiano. Por una conceptualización desde la justicia histórica. Conferencia Magistral, Universidad Central, Bogotá, Instituto de Estudios Sociales Contemporáneos (Iesco), 2018.

ARBOLEDA, S. Defensa Ambiental, Derechos Humanos y Ecogenoetnocidio Afrocolombiano. Pesquisa em Educação Ambiental, vol.13, n.1 - pags. 10-27, 2018b

BANCO MUNDIAL. Afrodescendientes en Latinoamérica. Hacia un marco de inclusión. Washington, DC: Banco Internacional de Reconstrucción y Fomento/Banco Mundial, 2018.

BUQUET, A; MONTIEL, S. y AGUILAR, G. Educación superior y perspectiva de género. En Carvajal Orlich, et al. (Eds.). Guía para acompañar procesos de sensibilización sobre inclusión social y equidad desde la perspectiva interseccional. (pp. 25-38). Costa Rica: MISEAL, 2014.

COMISIÓN INTERAMERICANA DE DERECHOS HUMANOS (CIDH). Informe sobre pobreza y derechos humanos en las Américas. OEA/Ser.L/V/II.164 Doc. 147, 2017.

LACLAU, E. La razón populista. Buenos Aires, FCE, 2005.

NATANSON, J. Cuando la desigualdad es una elección popular. Lemonde Diplomatique. Edicción. JULIO 2017 | N²17, 2017. 
MBEMBE, A. Necropolítica. Editorial Melusina. Barcelona, 2011.

OCORÓ, LOANGO, A. El reconocimiento de los afrodescendientes en la Argentina un estudio en perspectiva latinoamericana (Tesis doctoral no publicada). FLACSO, Argentina, 2014.

OCORÓ, LOANGO, A. Los afrodescendientes en Argentina: la irrupción de un nuevo actor en la agenda política y educativa del país. Revista Colombiana de Educación, 69, 137-157, 2015.

OCORÓ, LOANGO, A. La Negritud más allá del color. Usos, significados y apopriaciones de la categoría afrodescendiente en la Argentina. Revista Norus. Novos Rumos Sociológicos, 4, (5), 182-197, 2016.

OCORÓ, LOANGO, A. Del kirchnerismo al macrismo: afrodescendientes, política y estado en la Argentina. Colección Antologías del Pensamiento Social Latinoamericano y Caribeño Serie Pensamientos Silenciados: Afrodescendencias voces en resistencia en homenaje al centenario de Nelson Mandela. Rosa Campoalegre Septien (Editora). Consejo Latinoamericano de Ciencias Sociales CLACSO. P.p 267-287, 2018.

OFICINA INTERNACIONAL DEL TRABAJO. La hora de la igualdad en el trabajo. Informe global con arreglo al seguimiento de la Declaración de la OIT relativa a los principios y derechos fundamentales en el trabajo. Conferencia Internacional del Trabajo, Ginebra, 2003.

CEPAL. La matriz de la desigualdad social en América Latina. I Reunión de la Mesa Directiva de la Conferencia Regional sobre Desarrollo Social de América Latina y el Caribe Santo Domingo, 1 de noviembre de 2016. Santiago de Chile: CEPAL, 2016.

ONU - CEPAL. Situación de las Personas Afrodescendientes en América Latina y desafíos de políticas para la garantía de sus derechos. Santiago de Chile: CEPAL. 2017.

PROGRAMA DE LAS NACIONES UNIDAS PARA EL DESARROLLO (PNUD). Informe sobre Desarrollo Humano 2016. Desarrollo humano para todas las personas. Nueva York, Estados Unidos, 2016.

PROGRAMA DE LAS NACIONES UNIDAS PARA EL DESARROLLO (PNUD). Las trabajadoras del hogar remuneradas en el Cono Sur: lucha y superación de exclusiones históricas. Cuaderno de apoyo preparado para el Informe Regional sobre Desarrollo Humano para América Latina y el Caribe 2016. Cuaderno No. 1, Igualdad de Género. Nueva York, Estados Unidos, 2017.

PROGRAMA DE NACIONES UNIDAS PARA EL DESARROLLO - PNUD. Panorama general Informe sobre Desarrollo Humano 2019. Más allá del ingreso, más allá de los promedios, más allá del presente: Desigualdades del desarrollo humano en el siglo XXI, 2019.

SCOTT, J. El género: una categoría útil para el análisis histórico. En Cangiano y DuBois (comps.) De mujer a género (p. 17-50). Buenos Aires: Centro Editor de América Latina, 1993. 
WADE, P.. Multiculturalismo y racismo. Revista Colombiana de Antropología, 47 (2), 15-37. 2011.

\section{Referencias de diarios electrónicos}

VIEL, R. Manuel Loff: El bolsonarismo puede expandirse a cualquier sociedad de América Latina. Agencia de Periodismo Investigativo, 2019. Disponible en: https://ojo-publico.com/1345/elbolsonarismo-puede-expandirse-a-cualquier-sociedad-de-america-latina. Acesso en septiembre 20 de 2020.

PÁGINA 12. Jeanine Áñez los calificó de "héroes", al conmemorar el 53 aniversario de su muerte. El Gobierno de facto de Bolivia homenajeó a los militares que mataron al Che Guevara. Disponible en: https://www.pagina12.com.ar/298141-el-gobierno-de-facto-de-boliviahomenajeo-a-los-militares-qu Acceso en: octubre 09 de 2020

PÁGINA 12. Golpe en Bolivia: el racismo en la Operación "Los lujos de Evo". Disponible en: https://www.pagina12.com.ar/231564-golpe-en-bolivia-el-racismo-en-la-operacion-los-lujosde-evo. Acceso, septiembre 27 de 2020.

LA NACIÓN. González Fraga: Le hicieron creer al empleado medio que podía comprarse plasmas y viajar al exterior. Disponible en: https://www.lanacion.com.ar/economia/gonzalezfraga-le-hicieron-creer-al-empleado-medio-que-podia-comprarse-plasmas-y-viajar-al-exteriornid1903034/Acceso en: octubre 03 de 2020.

LA NACIÓN. Entrevista. François Dubet: No sólo somos víctimas de desigualdades, somos también sus autores. Disponible en: https://www.lanacion.com.ar/opinion/francois-dubet-nosolo-somos-victimas-de-desigualdades-somos-tambien-sus-autores-nid1822802/. Acceso en septiembre 30 de 2020.

EL CRONISTA. Dura respuesta de Cornejo a Fernández: "el preonismo de hoy representa al sector parasitario". Diponible en: https://www.cronista.com/economiapolitica/Dura-respuestade-Cornejo-a-Fernandez-El-peronismo-de-hoy-representa-al-sector-parasitario-202010180004.html. Acceso en octubre 21 de 2020. 